\title{
Pengaruh Motivasi dan Lingkungan Kerja terhadap Kepuasan Kerja di UKM Nahla Toys Cikampek
}

\author{
Firman Hidayat ${ }^{1}$, Maman Suryaman $^{2}$, Risma Fitriani $^{3}$, Billy Nugraha $^{4}$ \\ 1,2,3,4 Universitas Singaperbangsa Karawang \\ Jl. H.S. Ronggowaluyo, Kecamatan Telukjambe Timur, Kabupaten Karawang - 41361, Indonesia \\ e-mail: ${ }^{1}$ fhidayat288@gmail.com, ${ }^{2}$ maman.suryaman@fkip.unsika.ac.id, ${ }^{3}$ risma.fitriani@ft.unsika.ac.id, \\ ${ }^{4}$ billynugraha982@gmail.com
}

\begin{abstract}
Informasi Artikel $\quad$ Diterima: 07-01-2021 $\quad$ Direvisi: 21-01-2021 $\quad$ Disetujui: 25-01-2021
Abstrak

Penelitian ini terdapat dua variabel, yaitu $\mathrm{X}_{1}$ sebagai Motivasi Kerja dan $\mathrm{X}_{2}$ sebagai Lingkungan Kerja. Penelitian ini bertujuan untuk mengetahui pengaruh motivasi dan lingkungan kerja terhadap kepuasan kerja pada UKM Nahla Toys Cikampek. Data yang digunakan adalah data primer yang dikumpulkan melalui observasi, wawancara, menyebarkan kuisioner dan dokumentasi. Hipotesis dalam penelitian ini adalah pengaruh motivasi dan lingkungan kerja terhadap kepuasan kerja pada UKM Nahla Toys Cikampek. Untuk mengukur besarnya pengaruh variabel tersebut menggunakan regresi linier berganda dan bantuan program software IBM SPSS 25. Berdasarkan hasil analisis data, diperoleh nilai koefisien determinasi sebesar 5.05\%. Selain itu dengan nilai koefisien korelasi sebesar 0,711. Sementara hasil uji parsial (uji t) menunjukkan bahwa variabel lingkungan kerja berpengaruh signifikan terhadap kepuasan kerja. Hal ini diperoleh bahwa hasil $t$ hitung lebih besar dari $t$ tabel. Maka berdasarkan hasil tersebut dapat disimpukan bahwa lingkungan kerja berpengaruh terhadap kepuasan kerja karyawan pada UKM Nahla Toys Cikampek.
\end{abstract}

\section{Kata Kunci: IBM SPSS 25; Kepuasan Kerja; Lingkungan Kerja; Motivasi Kerja}

\begin{abstract}
This study contained two variables, namely X1 as Work Motivation and X2 as the Work Environment. This study aims to determine the influence of motivation and work environment on job satisfaction in SMEs Nahla Toys Cikampek. The Data used is primary data collected through observation, interview, distributing questionnaires and documentation. The hypothesis in this research is the influence of motivation and work environment on job satisfaction in SMEs Nahla Toys Cikampek. To measure the magnitude of influence of these variables using multiple linear regression and the help of the program software IBM SPSS 25. Based on the results of the data analysis, obtained value of the coefficient of determination amounted to 5.05\%. In addition to the value of the correlation coefficient amounted to 0.711 . While the results of partial test ( $t$ test) indicated that work environment variables have a significant effect on job satisfaction. It is obtained that the results of t count bigger than t table. Then based on these results it can be concluded that the work environment influence the job satisfaction of employees in SMES Nahla Toys Cikampek.
\end{abstract}

Keywords: IBM SPSS 25; Job Satisfaction; Motivation; Work Environment

\section{Pendahuluan}

Dalam menghadapi berbagai tantangan di era globalisasi, tempat usaha harus dapat meningkatkan kualitas sumber daya manusia dan memungkinkan memiliki keahlian khusus untuk meningkatkan keunggulan dari dalam dirinya (Ambar \& Rosidah, 2003). Usaha kecil dan menengah (UKM) telah terbukti di banyak negara/kawasan memiliki kemampuan menjadi pilar ekonomi kerakyatan yang mampu meredam dampak ekonomi global (Arikunto, 2010). Persaingan produk menjadi semakin tinggi dan perkembangan dunia bisnis menjadi semakin sulit dengan target yang begitu tinggi (Sutrisno, 2014;
Simamora, 2006). Setiap tempat usaha mewajibkan untuk dapat meningkatkan sumber daya manusia. Sumber daya manusia merupakan sumber daya dengan perasaan, keterampilan, pengetahuan dan motivasi (As'ad, 2004; Fathoni, 2006). Tanpa sumber daya manusia, sulit bagi suatu organisasi untuk mencapai tujuannya. Sumber daya manusia diperlukan manajemen yang sempurna, profesional dan teratur (Siagian, 2008; Hani, 2008). Hal ini untuk membuat keseimbangan antara kebutuhan dan perkembangan bisnis perusahaan. Sumber daya manusia yang terpenting dalam organisasi adalah seorang pegawai (Notoatmodjo, 2009). Pegawai 
adalah aset yang sangat berharga dan harus dikelola dengan baik oleh perusahaan untuk memberikan kontribusi terbaik. Salah satu faktor yang mempengaruhi loyalitas pegawai adalah motivasi (Mathis \& John, 2006; Hasibuan, 2013). Setiap orang harus termotivasi untuk melakukan tindakan tertentu. Motivasi itu sangat penting bagi pegawai agar pekerjaan yang diberikan dapat dilakukan dengan benar sesuai standar operasional perusahaan (Mangkuprawira, 2007; Mangkunegara, 2013). Indikator yang digunakan dalam variabel motivasi kerja sebagai berikut (Kartika \& Kaihatu, 2010):

a. Arah perilaku (direction of behavior), menjelaskan terhadap perilaku seorang pekerja dalam bekerja. Selain itu, untuk mencapai tujuan tertentu dari tempat kerja.

b. Tingkat usaha (level of effort), menjelaskan tentang kerja keras karyawan terhadap perilaku yang dipilihnya. Contoh penerapan dalam tingkatan ini seperti pekerja tidak cukup hanya memilih untuk selalu hadir tepat waktu.

c. Tingkat kegigihan (level of persistence), menjelasakan motivasi karyawan terhadap permasalahan pada pekerjaan. Contoh penerapan dalam tingkatan ini seperti jika terdapat kendala pada cuaca atau masalah terhadap kesehatan.

Lingkungan kerja merupakan tempat karyawan melakukan aktivitas setiap hari. Jika manusia mampu melakukan aktivitas dengan sebaikbaiknya, sehat, aman dan nyaman, maka pekerjaan dianggap sebagai pekerjaan yang baik atau pantas (Lumentut \& Dotulong, 2015). Indikator yang digunakan dalam variabel lingkungan kerja sebagai berikut (Gardjito, Musadieq, \& Nurtjahjono, 2014):

a. Penerangan, menjelaskan penerangan terhadap tempat kerja sangat penting. Dikarenakan dapat meningkatkan hasil yang kerja yang baik.

b. Udara, menjelasakan bahwa pekerja harus mendapatkan pertukaran udara yang baik. Jika udara dalam tempat kerja terdapat suhu yang terlalu panas, maka akan menurunkan semangat kerja karyawan.

c. Kebersihan, menjelaskan untuk menciptakan suasana yang nyaman. Sehingga semangat dalam pekerjaan akan terus meningkat.

Indikator yang digunakan dalam variabel kepuasan kerja sebagai berikut (Kartika \& Kaihatu, 2010):

a. Pekerjaan itu sendiri, menjelaskan bahwa pekerja menunjukkan keterampilan dan kemampuan yang dimiliki. Hal ini bertujuan agar meningkatkan kepuasan kerja.

b. Mutu pengawasan supervisi, menjelaskan bahwa atasan dalam tempat kerja mengawasi pekerjaan karyawan. Hal ini bertujuan untuk mengetahui pekerja dapat meningkatkan kepuasan kerja.

c. Gaji atau upah, menjelaskan hasil yang diperoleh selama bekerja sesuai dengan keterampilan yang dimiliki atau sebaliknya. Karena semua menentukan dalam kepuasan kerja karyawan. d. Kesempatan promosi, menjelaskan bahwa pekerja pantas atau tidak jika keterampilan yang dimiliki terus bertambah dan dapat berpindah jabatan.

e. Rekan kerja, menjelaskan bahwa seluruh manusia memerlukan bantuan dari orang lain yang artinya dalam sebuah pekerjaan juga membutuhkan rekan kerja yang baik agar dapat meningkatkan kepuasan kerja karyawan.

Dengan demikian, penelitian ini dilakukan di UKM Nahla Toys Cikampek yang terletak di wilayah Kecamatan Cikampek, Kabupaten Karawang. UKM Nahla Toys Cikampek merupakan usaha kecil dan menengah yang bergerak di bidang pembuatan boneka. UKM tersebut didirikan pada tahun 2011 dan memproduksi berbagai macam jenis boneka. Seperti boneka doraemon dan boneka dholpin. Selain itu macam-macam jenis boneka bisa berganti dalam sewaktu-waktu. Sementara proses produksi yang dilakukan memiliki beberapa tahapan. Seperti membuat pola, menjahit, membordir lalu diisi dengan busa, produk jadi dan pengepakan boneka. Berdasarkan hasil observasi terkait motivasi dan lingkungan kerja masih belum sesuai dengan harapan dan beban kerja yang dilakukan oleh pegawai. Berdasarkan hasil permasalahan di atas, maka penelitian ini bertujuan untuk mengetahui pengaruh motivasi dan lingkungan kerja terhadap kepuasan kerja pada UKM Nahla Toys Cikampek.

Berikut beberapa hasil penelitian terdahulu yang dijadikan parameter dalam penelitian. Penelitian yang dilakukan oleh Sopan Nugroho dan Asih Handayani: Komitmen karyawan tidak dapat memediasi pengaruh tidak langsung budaya kerja terhadap kinerja (Nugroho \& Handayani, 2020). Penelitian yang dilakukan oleh Gazali, Masduki Asbari dan Dewiana Novitasari: Hasil penelitian ini menimpulkan bahwa kepemimpinan transformasional berpengaruh positif dan signifikan terhadap kinerja karyawan (Gazali, Asbari, \& Novitasari, 2020). Penelitian yang dilakukan oleh Galih Raspati, Eva Marsusanti, Yuyun Yuniati dan Andi Riyanto: Temuan yang didapatkan dari penelitian adalah adanya efek yang secara simultan antara kepemimpinan, budaya organisasi dan kepuasan kerja terhadap kinerja (Raspati, Marsusanti, Yuniati, \& Riyanto, 2020). Penelitian yang dilakukan oleh Kartika Yuliantari dan Ines Prasasti: Hasil penelitian terdapat arah hubungan lingkungan kerja terhadap kinerja adalah positif, artinya searah (Yuliantari \& Prasasti, 2020). Penelitian yang dilakukan oleh Suwarsito: Kepuasan motivasi dan kenyamanan lingkungan kerja dapat memberikan stimulasi pekerja yang baik (Suwarsito, 2020).

Sedangkan di bawah ini hasil penelitian terdahulu yang dijadikan sebagai alternatif parameter dalam penelitian. Penelitian yang dilakukan oleh Edi Halomoan Irianto: Metode pengolahan dan analisis data menggunakan SPSS versi 19 (Irianto, 2020). Penelitian yang dilakukan oleh Galih Wicaksono: Sebesar 59,8\% perubahan yang terjadi pada prestasi 
kerja Relawan Pajak Tax Center Universitas Jember dijelaskan dengan baik oleh kompetensi dan pelatihan (Wicaksono, 2020). Penelitian yang dilakukan oleh Ningrum Rahayu dan Kartin Aprianti: Nilai sig dari output SPSS sebesar 0,0000 ternyata lebih kecil dari 0,05 (sig. $0,00<0,05$ ) maka dinyatakan terdapat pengaruh signifikan dari motivasi kerja terhadap kepuasan kerja (Rahayu \& Aprianti, 2020). Penelitian yang dilakukan oleh Renny Hermawati dan Suganjar: Hasil yang didapatkan menunjukkan bahwa motivasi, kompensasi serta pengembangan SDM secara statistik berpengaruh signifikan positif terhadap kepuasan kerja (Hermawati \& Suganjar, 2020). Penelitian yang dilakukan oleh Mochamad Hanafi: Penelitian menggunakan metode deskriptif kualitatif (Hanafi, 2020).

Pembaharuan dalam penelitian ini adalah pengolahan data yang dilakukan menggunakan bantuan software. Hal ini bertujuan agar pengujian data menunjukkan hasil yang akurat dan optimal. Software yang digunakan adalah IBM SPSS 25 (Ghozali, 2010). Pemilihan software ini dikarenakan menyediakan pengujian data secara statistik. Hal ini didasarkan dalam penelitian menggunakan metode regresi linier berganda. Selain itu dilakukan pengujian lain sebelum dilakukan uji regresi linier berganda. Sebelum dilakukan uji regresi linier berganda dilakukan uji analisis kuantitatif yang bersifat umum. Namun uji asumsi klasik yang masih diabaikan. Maka penelitian ini mencoba pembaharuan pengujian yang dilakukan dari penelitian sebelumnya.

\section{Metode Penelitian}

Penelitian ini dilakukan di UKM Nahla Toys yang beralamat di Kampung Mekar Jaya RT/RW 001/005, Dusun Cikampek Utara, Kecamatan Kotabaru, Kabupaten Karawang, Jawa Barat. Instrumen yang digunakan dalam penelitian ini adalah kuisioner. Sedangkan variabel yang menjadi perhatian pada penelitian ini adalah variabel bebas (independen) yaitu Motivasi $\left(\mathrm{X}_{1}\right)$ dan Lingkungan Kerja $\left(\mathrm{X}_{2}\right)$ serta variabel tidak bebas (dependen) yaitu
Kepuasan Kerja (Y). Penelitian ini menggunakan uji validitas dan uji reliabilitas yang bertujuan untuk mengetahui variabel-variabel yang digunakan telah layak dalam model regresi linier berganda. Selain itu dilakukan uji asumsi klasik diantaranya uji normalitas, uji multikolinearitas dan uji heteroskedastisitas. Untuk uji hipotesis penelitian ini menggunakan uji f, uji t dan koefisien determinasi. Sedangkan untuk analisis data menggunakan regresi linier berganda serta menggunakan software IBM SPSS 25. Pengaruh dari variabel yang diteliti berdasarkan nilai keofisien determinasi sebesar $71,1 \%$. Hal ini dapat dijadikan parameter bahwa variabel independen yang dipilih berpengaruh terhadap variabel dependen Berdasarkan hasil kajian di atas maka dapat dibuat kerangka berpikir seperti Gambar 1. Hal ini memperlihatkan hubungan atau pengaruh motivasi dan lingkungan kerja terhadap kepuasan kerja pada UKM Nahla Toys Cikampek.

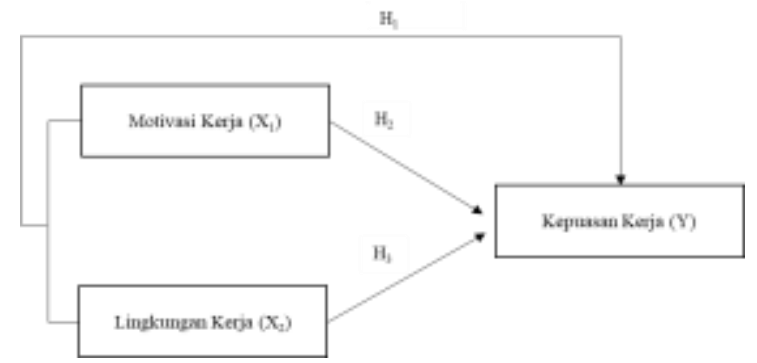

Sumber : Hasil Pengolahan Penulis (2021)

Gambar 1 : Kerangka Pemikiran

\section{Hasil dan Pembahasan}

3.1. Deskripsi Karakteristik Responden Jumlah responden yang dipilih dalam penelitian ini sebanyak 15 orang dengan identitas sebagai berikut:

1. Berdasarkan Jenis Kelamin Responden

Untuk mengetahui perbandingan antara jenis kelamin laki-laki dan perempuan, dapat dilihat pada Tabel 1:

Tabel 1. Jenis Kelamin Responden

\begin{tabular}{clrrrr}
\hline & Frequency & Percent & Valid Percent & $\begin{array}{r}\text { Cummulative } \\
\text { Percent }\end{array}$ \\
\hline \multirow{2}{*}{ Valid } & Laki-laki & 10 & 66.7 & 66.7 & 66.7 \\
& Perempuan & 5 & 33.3 & 33.3 & 100.0 \\
& Total & 15 & 100.0 & 100.0 & \\
\hline
\end{tabular}

Sumber: Hasil Pengolahan Penulis (2021)

Berdasarkan Tabel 1, menjelaskan bahwa jumlah responden dari 15 responden meliputi 10 responden laki-laki $(66,7 \%)$ dan 5 responden perempuan $(33,3 \%)$.
2. Berdasarkan Umur Responden

Untuk mengetahui perbandingan umur responden, dapat dilihat pada Tabel 2: 
Tabel 2. Umur Responden

\begin{tabular}{|c|c|c|c|c|c|}
\hline & & Frequency & Percent & Valid Percent & $\begin{array}{c}\text { Cummulative } \\
\text { Percent }\end{array}$ \\
\hline \multirow[t]{4}{*}{ Valid } & $21-30$ tahun & 9 & 60.0 & 60.0 & 60.0 \\
\hline & & Frequency & Percent & Valid Percent & $\begin{array}{r}\text { Cummulative } \\
\text { Percent }\end{array}$ \\
\hline & 31 - 40 tahun & 6 & 40.0 & 40.0 & 100.0 \\
\hline & Total & 15 & 100.0 & 100.0 & \\
\hline
\end{tabular}

Sumber : Hasil Pengolahan Penulis (2021)

Berdasarkan Tabel 2 berarti bahwa jumlah responden dari 15 responden. Meliputi 9 responden $(60 \%)$ berumur 21-30 tahun dan 6 responden $(40 \%)$ berumur 31-40 tahun.
3. Berdasakan Lama Bekerja

Untuk mengetahui perbandingan lama bekerja responden, dapat dilihat pada Tabel 3. di bawah ini:

Tabel 3. Lama Bekerja

\begin{tabular}{clrrrr}
\hline & \multirow{2}{*}{ Frequency } & Percent & Valid Percent & $\begin{array}{c}\text { Cummulative } \\
\text { Percent }\end{array}$ \\
\hline \multirow{2}{*}{ Valid } & $13-18$ bulan & 1 & 6.7 & 6.7 & 6.7 \\
& $19-24$ bulan & 1 & 6.7 & 6.7 & 13.3 \\
& 25 bulan & 13 & 86.7 & 86.7 & 100.0 \\
Total & 15 & 100.0 & 100.0 & \\
\hline
\end{tabular}

Sumber : Hasil Pengolahan Penulis (2021)

Berdasarkan Tabel 3 berarti bahwa jumlah responden dari 15 responden. Meliputi 1 responden $(6,7 \%)$ lama bekerja $13-18$ bulan, 1 responden $(6,7 \%)$ lama bekerja $19-24$ bulan dan 13 responden $(86,7 \%)$ lama bekerja $>25$ bulan.

\subsection{Hasil Pengujian dan Pengolahan Data}

1. Uji Validitas

Uji validitas bertujuan untuk menganalisis sebuah item, lalu dikorelasikan dengan nilai total seluruh item. Seperti pada Tabel 4:

Tabel 4. Uji Validitas

\begin{tabular}{|c|c|c|c|}
\hline Pernyataan & r hitung & $\mathrm{r}$ tabel & Keterangan \\
\hline \multicolumn{4}{|c|}{ Motivasi Kerja $\left(\mathrm{X}_{1}\right)$} \\
\hline 1 & 0,702 & 0,514 & Valid \\
\hline 2 & 0,57 & 0,514 & Valid \\
\hline \multicolumn{4}{|c|}{ Motivasi Kerja $\left(\mathrm{X}_{1}\right)$} \\
\hline 3 & 0,777 & 0,514 & Valid \\
\hline 4 & 0,518 & 0,514 & Valid \\
\hline 5 & 0,565 & 0,514 & Valid \\
\hline \multicolumn{4}{|c|}{ Lingkungan Kerja $\left(\mathrm{X}_{2}\right)$} \\
\hline 1 & 0,879 & 0,514 & Valid \\
\hline 2 & 0,843 & 0,514 & Valid \\
\hline 3 & 0,752 & 0,514 & Valid \\
\hline 4 & 0,735 & 0,514 & Valid \\
\hline 5 & 0,913 & 0,514 & Valid \\
\hline \multicolumn{4}{|c|}{ Kepuasan Kerja (Y) } \\
\hline 1 & 0,679 & 0,514 & Valid \\
\hline 2 & 0,769 & 0,514 & Valid \\
\hline 3 & 0,533 & 0,514 & Valid \\
\hline 4 & 0,526 & 0,514 & Valid \\
\hline 5 & 0,558 & 0,514 & Valid \\
\hline 6 & 0,624 & 0,514 & Valid \\
\hline
\end{tabular}

Sumber : Hasil Pengolahan Penulis (2021)
Berdasarkan Tabel 4, menunjukkan bahwa seluruh item pertanyaan pada setiap variabel mendapatkan nilai lebih besar dari nilai ketentuan $r$ tabel sebesar 0,514. Sehingga seluruh butir pertanyaan dinyatakan valid.

\section{Uji Reliabel}

Uji reliabel bertujuan untuk menghitung crobanch's alpha dari masing-masing instrumen dalam suatu konstruk. Seperti pada Tabel 5:

Tabel 5. Uji Reliabel

\begin{tabular}{cccc}
\hline Variabel & R hitung & R tabel & Keterangan \\
\hline X1 & 0,555 & 0,514 & Reliabel \\
X2 & 0,877 & 0,514 & Reliabel \\
Y & 0,666 & 0,514 & Reliabel \\
\hline
\end{tabular}

Sumber : Hasil Pengolahan Penulis (2021)

Berdasarkan Tabel 5, diketahui nilai output yang didapat menunjukan bahwa setiap konstruk pertanyaan yang dihasilkan adalah reliabel.

3. Uji Normalitas

Uji normalitas bertujuan untuk melihat semua butir pertanyaan tersebut baik atau layak digunakan. Jika nilai signifikan yang didapat dari uji normalitas di atas 0,05 maka semua butir pertanyaan berdistribusi normal. Seperti pada Tabel 6 .

Tabel 6. Uji Normalitas

\begin{tabular}{llr}
\hline & & \multicolumn{2}{c}{$\begin{array}{c}\text { Unstandardized } \\
\text { Residual }\end{array}$} \\
\hline $\mathrm{N}$ & Mean & 15 \\
$\begin{array}{l}\text { Normal } \\
\text { Parameters }\end{array}$ & Std. & 2.2477600000 \\
& $\begin{array}{l}\text { Std } \\
\text { Deviation }\end{array}$ & .170 \\
Most Extreme & Absolute & \\
Differences & & \\
\hline
\end{tabular}




\begin{tabular}{lrr}
\hline & $\begin{array}{l}\text { Positive } \\
\text { Negative }\end{array}$ & .132 \\
& & .170 \\
\hline & & $\begin{array}{r}\text { Unstandardized } \\
\text { Residual }\end{array}$ \\
\hline Test Statistic & .170 \\
Asymp. Sig. (2- & $.200^{\text {c.d }}$ \\
failed) & & \\
\hline
\end{tabular}

failed)

c. Lillieefors Significante Correction.

$\mathrm{d}$. This is a lower bound of the true significance.

Sumber : Hasil Pengolahan Penulis (2021)
Tabel 6, mempunyai nilai ketentuan dengan signifikan 0,05. Berdasarkan data di atas menunjukan bahwa nilai signifikan sebesar 0,200 yang berarti seluruh variabel berdistribusi normal.

4. Uji Multikolinearitas

Jika nilai tolerance lebih besar dari > 0,10 maka artinya tidak terjadi multikolinieritas. Jika nilai VIF lebih kecil dari < 10,00 maka artinya tidak terjadi multikolinearitas. Seperti pada Tabel 7:

Tabel 7. Uji Multikolinearitas

\begin{tabular}{|c|c|c|c|c|c|c|c|c|}
\hline \multirow[b]{2}{*}{ Model } & & \multirow[b]{2}{*}{$\begin{array}{c}\text { Unstandardized } \\
\text { B }\end{array}$} & \multirow[b]{2}{*}{$\begin{array}{l}\text { Coefficients } \\
\text { Std. Error }\end{array}$} & \multirow[b]{2}{*}{$\begin{array}{c}\text { Standarized } \\
\text { Coefficients Beta }\end{array}$} & \multirow[b]{2}{*}{$\mathrm{T}$} & \multirow[b]{2}{*}{ Sig } & \multicolumn{2}{|c|}{ Collinearity Statistics } \\
\hline & & & & & & & Tolerance & VIF \\
\hline 1 & (Constant) & 2.458 & 7.302 & & .337 & .742 & & \\
\hline & Motivasi Kerja & .588 & .331 & .380 & 1.775 & .101 & .899 & 1.112 \\
\hline & $\begin{array}{l}\text { Lingkungan } \\
\text { Kerja }\end{array}$ & .506 & .220 & .492 & 2.298 & .040 & .899 & 1.112 \\
\hline
\end{tabular}

a. Dependent Variable: Kepuasan kerja

Sumber : Hasil Pengolahan Penulis (2021)

Berdasarkan Tabel 7, menunjukan bahwa nilai Tolerance 0,889 >0,10 artinya tidak terjadi Mmultikolinearitas. Sedangkan nilai VIF 1.112 < 10,00 artinya tidak terjadi multikolinearitas.
5. Uji Heteroskedastisitas

Uji heteroskedastisitas bertujuan untuk melihat apakah ada titik-titik yang membentuk sebuah pola tertentu. Seperti pada Gambar 2:

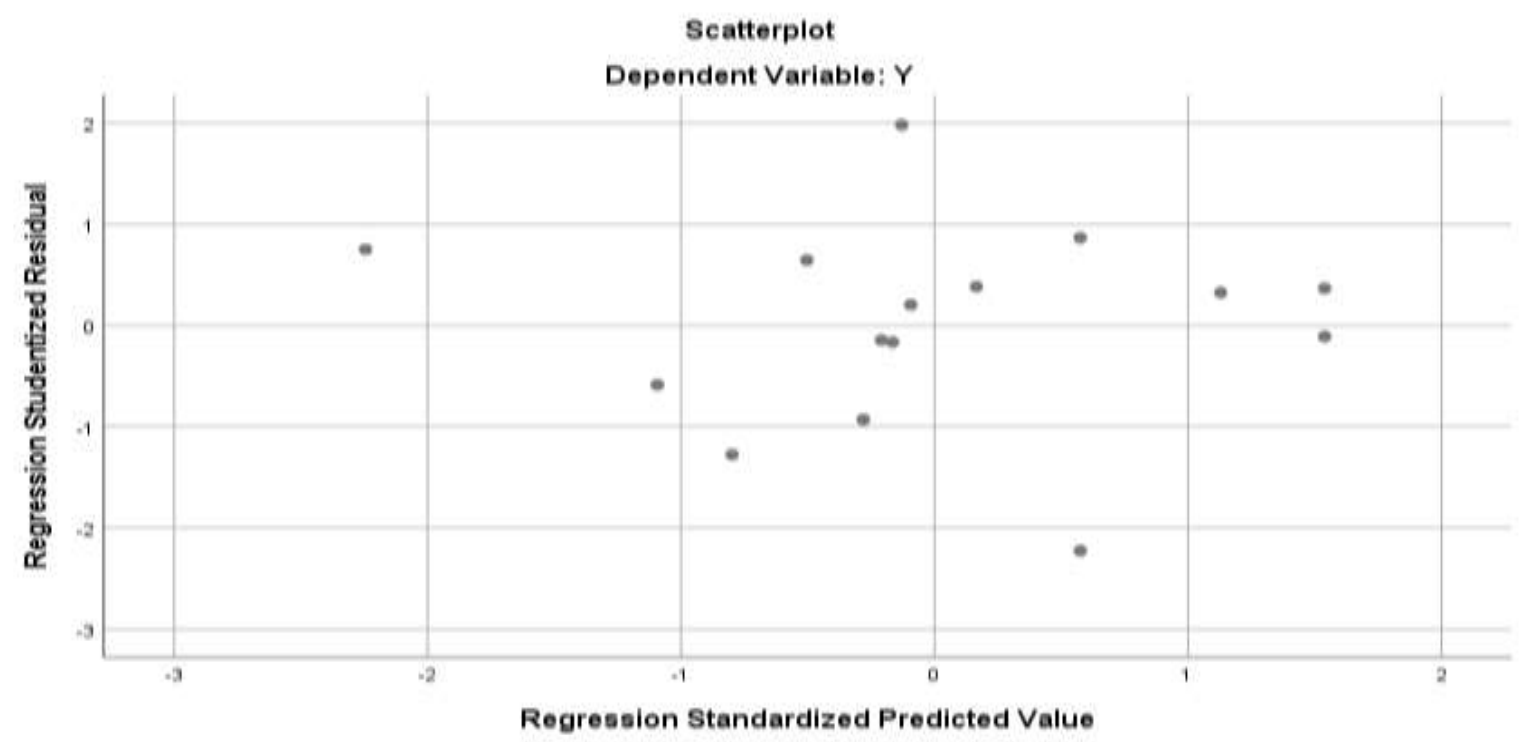

Sumber : Hasil Pengolahan Penulis (2021)

Gambar 2 : Uji Heteroskedastisitas

Berdasarkan uji heteroskesdastisitas menunjukan bahwa titik-titik menyebar dengan pola yang tidak jelas diatas dan dibawah angka 0 pada sumbu Y, jadi dapat disimpulkan bahwa tidak terjadi masalah heterokedastisitas pada model regresi.
6. Analisis Regresi Linier Berganda

Seberapa besar pengaruh variabel bebas yaitu Motivasi Kerja $\left(\mathrm{X}_{1}\right)$ dan Lingkungan Kerja $\left(\mathrm{X}_{2}\right)$ terhadap Kepuasan Kerja (Y). Seperti pada Tabel 8. di bawah ini: 
Tabel 8. Regresi Linier Berganda

\begin{tabular}{clrrrrr}
\hline \multirow{2}{*}{ Model } & & $\begin{array}{c}\text { Unstandardized } \\
\text { B }\end{array}$ & $\begin{array}{c}\text { Coefficients } \\
\text { Std. Error }\end{array}$ & $\begin{array}{c}\text { Standarized } \\
\text { Coefficients Beta }\end{array}$ & $\mathrm{t}$ & Sig \\
\hline 1 & (Constant) & 2.458 & 7.302 & .337 & .742 \\
& Motivasi Kerja & .588 & .331 & .380 & 1.775 & .101 \\
& Lingkungan Kerja & .506 & .220 & .492 & 2.298 & .040 \\
& & & & & & \\
\end{tabular}

Sumber : Hasil Pengolahan Penulis (2021)

Hasil persamaan regresi linier berganda, yaitu:

$\mathrm{Y}=2,458+0,588 \mathrm{X}_{1}+0,506 \mathrm{X}_{2}$

Berdasarkan Tabel 8. di atas, nilai kontan 2,458 artinya jika motivasi kerja, kompensasi kerja dan lingkungan kerja yang diteliti konstan, maka kepuasan kerja pegawai pada UKM Nahla Toys Cikampek sebesar 2,458. Nilai koefisien regresi motivasi sebesar 0,588 artinya, peningkatan motivasi kerja akan meningkatkan kepuasan kerja karyawan pada UKM Nahla Toys Cikampek sebesar 0,588 dan Nilai koefisien regresi lingkungan kerja sebesar 0,506 artinya, peningkatan atau penurunan lingkungan kerja akan mempengaruhi kepuasan kerja karyawan pada UKM Nahla Toys Cikampek sebesar 0,506.

7. Uji Simultan (Uji F)

Pengujian ini dilakukan dengan cara membandingkan angka taraf signifikan. Hasil perhitungan dengan taraf signifikan 0,05 (5\%) dengan kriteria Jika F hitung (sig) > 0,05. Maka H0 diterima dan Ha di tolak, dan jika F hitung (sig) < 0,05. Maka H0 ditolak dan Ha di terima. Seperti pada Gambar 9:

Tabel 9. Uji Simultan (Uji F)

\begin{tabular}{clrrrrr}
\hline \multirow{2}{*}{ Model } & & Sum of & df & Mean Square & F & \multicolumn{2}{c}{ Sig } \\
\hline \multirow{2}{*}{1} & Squares & 72.199 & 2 & 36.100 & 6.124 & $.015^{\text {b }}$ \\
& Residual & 70.734 & 12 & 5.895 & & \\
& Total & 142.933 & 14 & & & \\
\hline
\end{tabular}

b. Predictors: (Constant), Lingkungan kerja (X2), Motivasi Kerja (X1)

Sumber : Hasil Pengolahan Penulis (2021)

Berdasarkan Tabel 9, menunjukan bahwa nilai signifikansi untuk pengaruh variabel motivasi $\left(\mathrm{X}_{1}\right)$ dan lingkungan kerja $\left(\mathrm{X}_{2}\right)$ secara simultan 0,015 $<0,05$ dan nilai $\mathrm{F}$ hitung 6,124 > Ftabel 3,49. Sehingga bisa memberi kesimpulan bahwa. Hipotesis Kepuasan Kerja diterima yang berarti terdapat pengaruh $\mathrm{X}_{1}, \mathrm{X}_{2}$ secara simultan terhadap Kepuasan Kerja (Y).

8. Uji Parsial (Uji T)

Uji parsial digunakan untuk menguji pengaruh masing-masing variabel bebas. Penelitian ini menggunakan variabel yaitu Motivasi Kerja $\left(\mathrm{X}_{1}\right)$ dan Lingkungan Kerja $\left(\mathrm{X}_{2}\right)$ terhadap Kepuasan Kerja (Y) dengan cara melakukan perbandingan antara nilai-nilai thitung pada $\alpha=0,05$ atau membandingkan probabilitas pada taraf nyata $95 \%$ dari koefisien parsial (r). Sehingga dapat diketahui pengaruh variabel bebas secara individu dengan menggunakan kriteria uji hipotesis dengan uji t jika t hitung $<\mathrm{t}$ tabel $(0,05)$ maka H0 diterima. Sehingga Ha ditolak dan jika $t$ hitung $>\mathrm{t}$ tabel $(0,05)$, maka H0 ditolak sehingga Ha diterima. Seperti pada Tabel 10.

\begin{tabular}{|c|c|c|c|c|c|c|}
\hline Model & & $\begin{array}{c}\text { Unstandardized } \\
\text { B }\end{array}$ & $\begin{array}{l}\text { Coefficients } \\
\text { Std. Error }\end{array}$ & $\begin{array}{c}\text { Standarized } \\
\text { Coefficients Beta }\end{array}$ & $\mathrm{t}$ & Sig \\
\hline \multirow[t]{3}{*}{1} & (Constant) & 2.458 & 7.302 & & .337 & .742 \\
\hline & Motivasi Kerja & .588 & .331 & .380 & 1.775 & .101 \\
\hline & Lingkungan Kerja & .506 & .220 & .492 & 2.298 & .040 \\
\hline
\end{tabular}

Sumber : Hasil Pengolahan Penulis (2021)

Berdasarkan Tabel 10, menunjukan bahwa variabel Motivasi Kerja $\left(\mathrm{X}_{1}\right) \mathrm{t}$ hitung $>\mathrm{t}$ tabel $(1.775$
$>$ 2,201) dengan nilai signifikan 0,101 > 0,05. Berarti H0 ditolak dan variabel Motivasi Kerja tidak 
berpengaruh terhadap Kepuasan Kerja. Sedangkan variabel Lingkungan Kerja $\left(\mathrm{X}_{2}\right)$ menunjukkan bahwa t hitung $>\mathrm{t}$ tabel $(2.298>2,201)$ dengan nilai signifikan $0,040<0,05$ berarti H0 diterima dan variabel Lingkungan Kerja berpengaruh terhadap Kepuasan Kerja.

\section{Koefisien Determinasi}

Pengujian ini bertujuan untuk mengetahui seberapa besar nya variabel bebas terhadap variabel dependen. Seperti pada Tabel 11:

Tabel 11. Koefisien Determinasi

\begin{tabular}{ccccc}
\hline Model & $\mathrm{R}$ & $\mathrm{R}$ Square & Adjusted $\mathrm{R}$ Square & Std. Error of the Estimate \\
\hline 1 & $.711^{\mathrm{a}}$ & .505 & .423 & 2.428 \\
\hline
\end{tabular}

a. Predictors: (Constant), Lingkungan kerja (X2), Motivasi Kerja (X1)

Sumber : Hasil Pengolahan Penulis (2021)

Berdasarkan Tabel 11, memperlihatkan bahwa nilai R2 adalah sebesar 0,168. Nilai R2 ini yang berada diantara $0 \leq \mathrm{R} 2 \leq 1$ berarti bahwa garis regresi yang terbentuk dapat meramalkan variabel dependen Kepuasan Kerja (Y) sebesar 5,05\%, R sebesar 0,711 berarti bahwa hubungan antara variabel Motivasi Kerja $\left(\mathrm{X}_{1}\right)$ dan Lingkungan Kerja $\mathrm{X} 2$ terhadap kepuasan kerja (Y) sebesar $71,1 \%$ sisanya di pengaruhi oleh faktor lain yang tidak diteliti pada penelitian.

\subsection{Pembahasan Pengujian dan Pengolahan Data}

1. Motivasi Kerja dan Lingkungan Kerja Terhadap Kepuasan Kerja

Berdasarkan hasil perhitungan data yang telah dilakukan, menunjukan bahwa nilai signifikansi untuk pengaruh variabel motivasi $\left(\mathrm{X}_{1}\right)$ dan lingkungan kerja $\left(\mathrm{X}_{2}\right)$ secara simultan $0,015<0,05$ dan nilai $F$ hitung 6,124 > F tabel 3,49. Sehingga dapat disimpulkan bahwa variabel Kepuasan Kerja diterima yang berarti terdapat pengaruh $\mathrm{X}_{1}, \mathrm{X}_{2}$ secara simultan terhadap Kepuasan Kerja (Y) di UKM Nahla Toys Cikampek. Hasil hipotesis ini dikatakan berpengaruh karena (Suwarsito, 2020):

a. Jika Nilai $F$ hitung > Nilai F tabel, maka terdapat pengaruh variabel yang diteliti.

b. Jika Nilai F hitung < Nilai F tabel, maka tidak terdapat pengaruh variabel yang diteliti.

2. Motivasi Kerja Terhadap Kepuasan Kerja Berdasarkan hasil perhitungan data yang telah dilakukan, menunjukan bahwa variabel Motivasi Kerja $\left(\mathrm{X}_{1}\right) \mathrm{t}$ hitung $>\mathrm{t}$ tabel $(1.775>2,201)$ dengan nilai signifikan $0,101>0,05$. Sehingga dapat disimpulkan bahwa variabel Motivasi Kerja tidak berpengaruh terhadap Kepuasan Kerja di UKM Nahla Toys Cikampek. Hasil hipotesis ini dikatakan berpengaruh karena (Suwarsito, 2020):

a. Jika Nilai $\mathrm{t}$ hitung > Nilai $\mathrm{t}$ tabel, maka terdapat pengaruh variabel yang diteliti.

b. Jika Nilai t hitung < Nilai t tabel, maka tidak terdapat pengaruh variabel yang diteliti.

3. Lingkungan Kerja Terhadap Kepuasan Kerja Lingkungan Kerja $\left(\mathrm{X}_{2}\right)$ menunjukkan bahwa t hitung > t tabel $(2.298>2$ 201) dengan nilai signifikan $0,040<0,05$. Sehingga dapat disimpulkan bahwa variabel Lingkungan Kerja berpengaruh terhadap Kepuasan Kerja di UKM Nahla Toys
Cikampek. Hasil hipotesis ini dikatakan berpengaruh karena (Suwarsito, 2020):

a. Jika Nilai t hitung > Nilai t tabel, maka terdapat pengaruh variabel yang diteliti.

b. Jika Nilai t hitung < Nilai t tabel, maka tidak terdapat pengaruh variabel yang diteliti.

\section{Kesimpulan}

Berdasarkan hasil penelitian maka dapat diambil kesimpulan sebagai berikut: (1) Motivasi kerja dan lingkungan kerja secara simultan berpengaruh secara signifikan terhadap kepuasan kerja pada UKM Nahla Toys Cikampek. (2) Motivasi kerja tidak berpengaruh secara signifikan terhadap kepuasan kerja pada UKM Nahla Toys Cikampek. (3) Lingkungan kerja berpengaruh secara signifikan terhadap kepuasan kerja pada UKM Nahla Toys Cikampek dan diharapkan untuk penelitian selanjutnya dapat menambahkan variabel dependen yang lain seperti kompensasi kerja, disiplin kerja dan lain-lain.

\section{Referensi}

Ambar, T., \& Rosidah. (2003). Manajemen Sumber Daya Manusia. Yogyakarta: Graha Ilmu.

Arikunto, S. (2010). Prosedur Penelitian suatu Pendekatan Praktik. Jakarta: Rineka Cipta.

As'ad, M. (2004). Psikologi Industri (Seri Sumber Daya Manusia). Yogyakarta: Liberty.

Fathoni, A. (2006). Organisasi dan Manajemen Sumber Daya Manusia. Jakarta: Rineka Cipta.

Gardjito, A. H., Musadieq, M. A., \& Nurtjahjono, G. E. (2014). Pengarruh Motivasi Kerja dan Lingkungan Kerja terhadap Kinerja Karyawan. Jurnal Administrasi Bisnis, 1-8.

Gazali, Asbari, M., \& Novitasari, D. (2020). Peran Readness for Change Mentality terhadap Kinerja Pegawai Kontrak Industri Alas Kaki. Widya Cipta: Jurnal Sekretari dan Manajemen, 169182.

Ghozali, I. (2010). Aplikasi Analisi Multivariate dengan Program IBM SPSS. Semarang: Universitas Diponegoro.

Hanafi, M. (2020). Manajemen Sumber Daya Manusia SMK Bisnis dan Manajemen di Daerah Istimewa Yogyakarta. Jurnal Pendidikan Manajemen Perkantoran, 31-44. 
Hani, H. T. (2008). Manajemen Personalia dan Sumber Daya Manusia. Yogyakarta: BPFE UGM.

Hasibuan, M. S. (2013). Manajemen Sumber Daya Manusia. Jakarta: Bumi Aksara.

Hermawati, R., \& Suganjar. (2020). Analisis Pengaruh Motivasi, Kompensasi, dan Pengembangan SDM Terhadap Kinerja Anak Buah Kapal Deck Departement Melalui Variabel Intervening Kepuasan Kerja. Majalah Ilmiah Bahari Jogja, 1-13.

Irianto, E. H. (2020). Pengaruh Iklim Organisasi, Kompetensi, dan Motivasi Kerja Terhadap Kinerja Pegawai BPP Aparatur Sukamandi. Widya Cipta: Jurnal Sekretaria dan Manajemen, 40-48.

Kartika, E. W., \& Kaihatu, T. S. (2010). Analisis Pengaruh Motivasi Kerja terhadap Kepuasan Kerja (Studi Kasus pada Karyawan Restoran di Pakuwon Food Festival Surabaya). Jurnal Manajemen dan Kewirausahaan, 100-112.

Lumentut, M. D., \& Dotulong, L. O. (2015). Pengaruh Motivasi, Disiplin dan Lingkungan Kerja terhadap Kepuasan Kerja Karyawan pada PT. Bank Sulut Cabang Airmadidi. Jurnal EMBA, 74-85.

Mangkunegara, A. P. (2013). Manajemen Sumber Daya Manusia Perusahaan. Bandung: Remaja Rosdakarya.

Mangkuprawira, S. (2007). Manajemen Mutu Sumber Daya Manusia. Bogor: Ghalia Indonesia.

Mathis, R. L., \& John, H. J. (2006). Manajemen Sumber Daya Manusia. Jakarta: Salemba Empat.

Notoatmodjo, S. (2009). Pengembangan Sumber Daya Manusia. Jakarta: Rineka Cipta.

Nugroho, S., \& Handayani, A. (2020). Pengaruh Budaya Kerja dan Kepuasan Kerja terhadap
Kinerja Karyawan dengan Komitmen Karyawan sebagai Variabel Mediasi pada Dinas Pemberdayaan Masyarakat dan Desa Kabupaten Ponorogo. Jurnal Manajemen Sumber Daya Manusia, 1-14.

Rahayu, N., \& Aprianti, K. (2020). Pengaruh Motivasi Kerja Terhadap Kepuasan Kerja Karyawan pada PT. Perum Pegadaian Salama Cabang Bima. Jurnal Manajemen Sumber Daya Manusia, 1-6.

Raspati, G., Marsusanti, E., Yuniati, Y., \& Riyanto, A. (2020). Efek Kepemimpinan, Budaya Organisasi dan Kepuasan Kerja terhadap Kinerja. Widya Cipta: Jurnal Sekretaria dan Manajemen, 92-98.

Siagian, S. P. (2008). Manajemen Sumber Daya Manusia. Jakarta: Bumi Aksara.

Simamora, H. (2006). Manajemen Sumber Daya Manusia. Yogyakarta: YKPN.

Sutrisno, E. (2014). Manajemen Sumber Daya Manusia. Jakarta: Kencana.

Suwarsito. (2020). The Role of Work Environment and Work Motivation in Increasing Employee Performance. Widya Cipta: Jurnal Sekretaria dan Manajemen, 70-75.

Wicaksono, G. (2020). Pengaruh Kompetensi dan Pelatihan Terhadap Prestasi Kerja Relawan Pajak Tax Center Universitas Jember. Widya Cipta: Jurnal Sekretaria dan Manajemen, 6469.

Yuliantari, K., \& Prasasti, I. (2020). Pengaruh Lingkungan Kerja terhadap Kinerja Karyawan pada LLDIKTI Wilayah III Jakarta. Widya Cipta: Jurnal Sekretaria dan Manajemen, 7682. 